\title{
Participatory Action Research Applied to an Ear, Nose, and Throat Specialty Service Redesign in Remote Australia: A Mixed-Methods Study of Key Stakeholder Perspectives
}

\author{
Susan P. Jacups 1,2 , Irina Kinchin ${ }^{3,4,5}$ a and Layla Edwards $5, *(\mathbb{D}$ \\ 1 School of Public Health, University of Queensland, Herston, QLD 4006, Australia; s.jacups@uq.edu.au \\ 2 The Cairns Institute, James Cook University, Smithfield, QLD 4879, Australia \\ 3 Centre for Health Economics Research and Evaluation (CHERE), University of Technology Sydney, \\ Ultimo, NSW 2007, Australia; kinchini@tcd.ie \\ 4 School of Medicine, Trinity College Dublin, the University of Dublin, College Green, Dublin 2, Ireland \\ 5 Centre for Improving Palliative, Aged and Chronic Care through Clinical Research and \\ Translation (IMPACCT), University of Technology Sydney, Ultimo, NSW 2007, Australia \\ * Correspondence: layla.edwards@uts.edu.au
}

check for

updates

Citation: Jacups, S.P.; Kinchin, I.; Edwards, L. Participatory Action Research Applied to an Ear, Nose, and Throat Specialty Service Redesign in Remote Australia: A Mixed-Methods Study of Key Stakeholder Perspectives. Int. J. Environ. Res. Public Health 2021, 18, 167. https://doi.org/10.3390/ijerph 18010167

Received: 12 November 2020 Accepted: 21 December 2020 Published: 29 December 2020

Publisher's Note: MDPI stays neutral with regard to jurisdictional claims in published maps and institutional affiliations.

Copyright: () 2020 by the authors. Licensee MDPI, Basel, Switzerland. This article is an open access article distributed under the terms and conditions of the Creative Commons Attribution (CC BY) license (https: / / creativecommons.org/ licenses/by/4.0/).

\begin{abstract}
This mixed-methods study reports on the key stakeholders' perspectives on the ear, nose, and throat (ENT) service redesign in remote Australia, using a participatory action research (PAR) approach. A primary health care (PHC) clinician survey was conducted to assess local needs and possible educational gaps in clinical knowledge. This was followed by an internal stakeholder forum and a follow-up survey with Torres and Cape Hospital and Health Service staff to gain their perspectives on current service delivery and table ideas for a new ENT health service model. Qualitative data were analyzed inductively and grouped in emerging themes. Quantitative data were imported into tables and analyzed descriptively. PAR allowed for input from 19 PHC clinicians, 10 face-to-face stakeholders perspectives, and 18 stakeholder follow-up survey respondents. Four themes emerged: 1. Training for health workers in ENT management; 2 . Improved local service access; 3 . New referral pathways to improve continuity of care; and 4. Introduction of telehealth. PAR engaged key stakeholders, identifying gaps in ENT service delivery, and guided the development of the new service model. The inclusion of stakeholders throughout the service redesign process is likely to create a more sustainable model of care which already has local "buy-in".
\end{abstract}

Keywords: participatory action research; service redesign; health promotion; ear; nose; throat; ear and hearing health; rural health services; indigenous health; telehealth; stakeholder perspectives; qualitative

\section{Introduction}

\subsection{Evidence Base}

Health care delivery in rural and remote locations across Australia has established difficulties [1]. Specifically, residents of these areas experience challenges accessing health services and personal high out-of-pocket costs associated with transport to travel extensive distances [2,3]. The Cape York region in North Queensland covers an area of 113,023 square kilometers (see Figure 1). It supports a population of over 11,000 people, of whom 58\% are Aboriginal or Torres Strait Islander people (hereafter, respectfully, Indigenous) [4]. Health inequalities in rural and remote settings in Australia are well researched [1,5]. The Cape York region is no exemption, with an average of 10 years lower health adjusted life expectancy than the Queensland state level [6]. In particular, the region reports high rates of otitis media (middle ear infection), often with associated hearing loss [7]. Despite this, access to ear, nose, and throat (ENT) services across the region is insufficient [7]. 


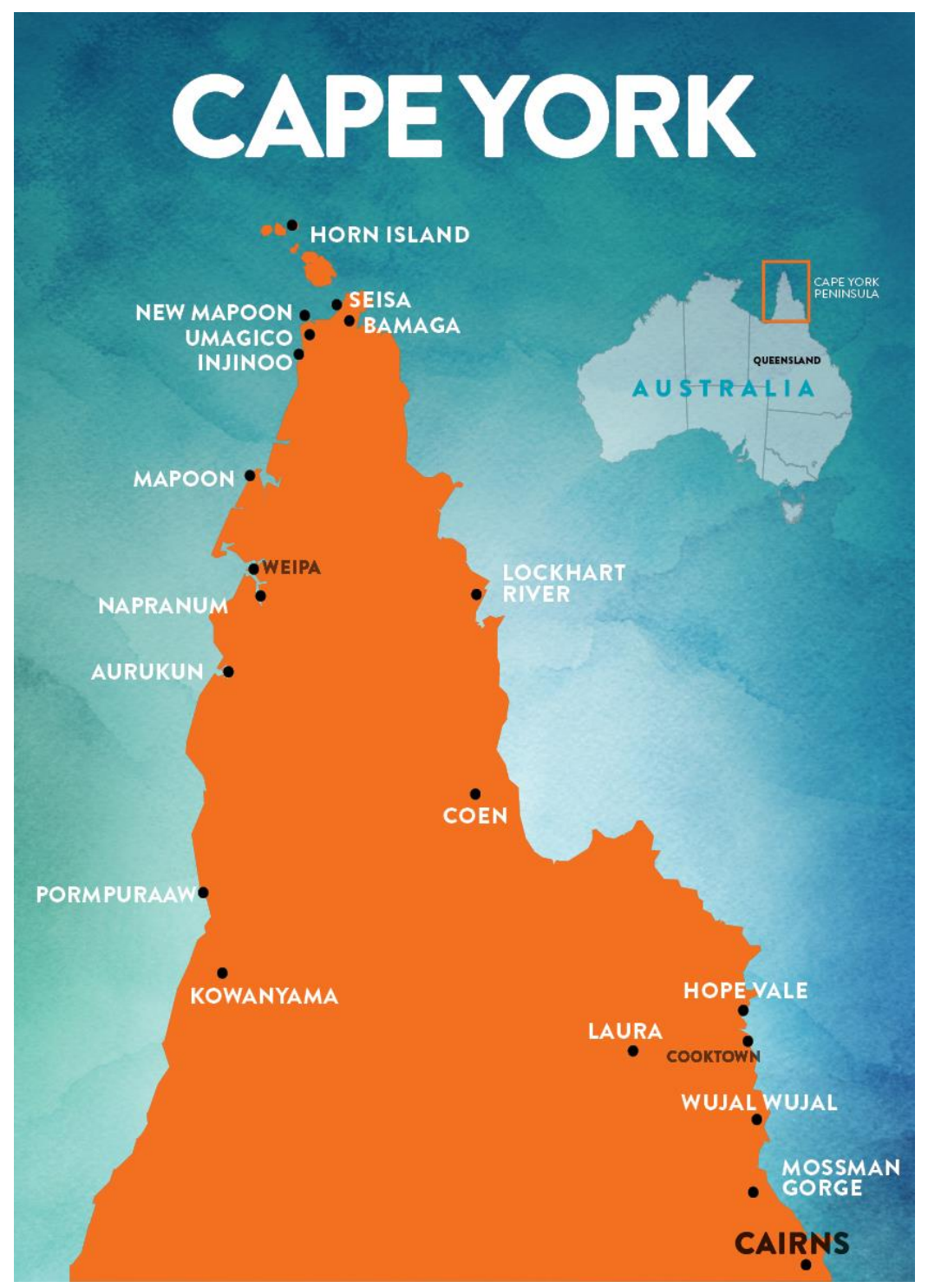

Figure 1. Map of Cape York Peninsula, North Queensland, Australia.

\subsection{Current Service Delivery Model of Care for ENT}

In 2017, specialist ENT outreach services were provided to only two (15\%) Cape York communities (Wujul Wujul and Hope Vale) via the Queensland Health Deadly Ears program (Figure 1) [8,9]. People who live in the other 11 Cape York communities or townships must travel to these communities, which may include a driving distance of over 800 kilometers, to attend a face-to-face outpatient ENT specialist appointment [10]. The Deadly Ears program offers biannual ENT team visits to each community for ear and hearing screening of Indigenous children [8]. The Deadly Ears team includes specialist ENT nurses and audiologists who work alongside an ENT surgeon. In Cape York, the Deadly Ears program does not offer surgery; instead, they refer patients to the closest level 5 hospital [8]. At the time this project was undertaken, there were no outreach or telehealth services available for ENT review across Cape York, largely due to resistance within the ENT department to offer these services.

The referral hospital is challenged with long waiting times for ENT outpatient clinics and staff shortages [11]. We have previously documented the high rates of ear disease and poor hearing outcomes in this population, with ear perforations (in one or both ears) in 7\% of school-aged children [7]. In addition, poor access to services has been reported, with waiting times of up to three years for elective ENT surgery [7]. Recent waiting times 
for children (aged 0-21) indicate breaches to categorization times [12] in over 82 percent of referrals (unpublished Queensland Health data, 2017). The Torres and Cape Hospital and Health Service employs one ENT administrator to assist and coordinate remote Cape York patient attendance at ENT outpatient appointments and surgery at the referral hospital. Both the outpatient appointments and surgery report a high fail-to-attend rate for ENT outpatient appointments, reported at 19 percent (May-July 2017, unpublished Queensland Health data).

As the current service model for ENT service delivery was insufficient to meet population needs, a service model redesign project was commissioned to create an informed new service delivery model for ENT services within Cape York. The new model aims to streamline services and build local capacity by offering local clinical ear and hearing training to improve clinician confidence when managing presenting ear and hearing conditions. This paper reports on the key stakeholders' perspectives on the ENT service redesign, using a participatory action research (PAR) approach. Participatory action research is defined as a "collective, self-reflective inquiry that researchers and participants undertake, so they can understand and improve upon the practices in which they participate and the situations in which they find themselves. This reflective process is directly linked to action, influenced by understanding of history, culture, and local context and embedded in social relationships" [13]. Due to the ear health disparity in the area, PAR was chosen because it allows service users to provide input into defining the scope and context of the project (service redesign) and the output of the newly designed ENT service model [13-15]. The involvement of stakeholders in health service redesign influences the quality, dissemination, and contextualization of findings and, therefore, contributes to the sustainability of the service delivery [16]. Furthermore, PAR can improve worker satisfaction and lead to better quality outputs, which are sustained [17]. Thus, the aim of this mixed-methods study is (1) to outline primary health care clinicians' current ENT concerns; (2) to gain ENT stakeholders' perspectives in the current gaps and barriers to ENT services in the region; and (3) to make recommendations for a new ENT service model.

\section{Materials and Methods}

In this mixed-methods study, an initial primary health care (PHC) clinician's survey was conducted to elicit current ENT concerns. The PHC clinician survey was followed by a stakeholder discussion forum and a follow-up stakeholder survey to thoroughly assess gaps and barriers to current ENT service delivery, and to make recommendations for a new ENT service model. The redesign project adopted a PAR framework to inform the development of a new sustainable, evidence-based model of care for ENT services across Cape York. Participation in this study was voluntary, and no additional remuneration was provided.

\subsection{Initial PHC Staff Perspective Survey}

In order to thoroughly assess local needs and possible educational gaps in clinical knowledge, a staff perspective online survey was distributed via SurveyMonkey (SVMK Inc., San Mateo, CA, USA) in January 2017. It was emailed directly to the ear or hearing PHC clinicians who provide services across Cape York from the Child and Maternal Health network group email list. At the time this survey was distributed, there were 80 members in the Child and Maternal Health network group. However, it should be noted that, due to a high turnover of staff in the region, we cannot be sure all 80 email addresses were active and received the PHC clinician survey. The survey sought information from clinicians on their level of confidence screening, diagnosing, and delivering ear and hearing treatments. The survey consisted of 15 multiple choice questions, while offering open-ended comments sections for an optional more detailed response (for full survey questions, refer to Supplementary File S1). 


\subsection{Stakeholder Open Forum and Follow-up Survey}

A half-day internal stakeholder forum took place in Cairns in September 2017. Stakeholders were Torres and Cape Hospital and Health Service staff who were directly involved with clinical care or coordination (administration and data management system) of ENT services in Cape York. Potential stakeholders were recruited via email and invited to describe their views on current service delivery and identify potential solutions that could be incorporated into the development of the new ENT health service model [17]. Stakeholders were identified by the Queensland Health directory database. The forum was guided by reviewing the results from the PHC staff perspective survey, which led to stakeholders identifying gaps and barriers to current ENT service delivery. Potential solutions to identified issues were tabled, as well as alternate service delivery models. In-depth discussions led stakeholders to develop a new model which aimed to improve health and reduce health inequities for people in the Cape York region [7,18-24].

The forum responses formed the questions that were later offered in the follow-up stakeholder survey, which was distributed a week after the forum. The aim was to gain further input on their priorities for future ENT services. An email link to SurveyMonkey was sent to the invited forum participants, to reiterate their input and provide an opportunity to add input for those who could not attend the forum. Follow-up survey participants were further asked about the current gaps/barriers to ENT service delivery in Cape York, and what services they would like to see in an ENT outreach and surgical service within Cape York.

\subsection{Data Collection and Analysis}

The initial PHC clinician survey was analyzed prior to the forum. Quantitative data captured on the online survey were exported into, and analyzed descriptively using, Microsoft Excel. Additional comments made in the survey were extracted into a table in Microsoft Word and analyzed thematically. The forum was recorded and transcribed, verbatim, by health service administration. Handwritten notes and minutes were also taken and added to the qualitative data analysis. The follow-up survey responses were combined with the stakeholder forum data and stored in SurveyMonkey. Together, the combined qualitative data were analyzed inductively and grouped into emerging themes by two independent investigators. Any conflicting opinions among the authors were resolved through discussion.

\subsection{Ethics}

This study was reviewed by the Far North Queensland Human Research Ethics Committee and granted an exemption from full ethical review, as it meets criteria as a quality improvement activity; reference number HREC/17/QCH/3-1111 QA. Any activity where the primary purpose is to improve the quality of service delivered by an individual or organization may apply for a quality improvement exemption [25]. Therefore, participation in the survey, open forum, and follow-up survey was voluntary, and informed consent was not necessary for participation. As a result of this, no demographics of participants were collected, and qualitative data is non-identified.

\section{Results}

\subsection{PHC Staff Perspective Survey}

A total of 19 PHC clinicians responded to the initial survey. The respondents were from a range of clinical professions, including clinical nurses (42\%), medical officers (16\%), and indigenous health workers (11\%) (see Appendix A., Table A1 for full survey responses).

\subsubsection{Assessing, Diagnosing, and Management of Ear Conditions}

Half of the respondents (44\%) had limited confidence in the assessments of ear or hearing conditions (Figure 2 and Table A1). Furthermore, half of the respondents (range: $42-48 \%$ ) reported they lacked confidence in using the necessary equipment to assess ear 
and hearing conditions. Forty-four percent (44\%) of the respondents reported the highest level of uncertainty when diagnosing or assessing otitis media with effusion, and $22 \%$ of respondents felt unsure of the remaining conditions. A third (32\%) of respondents also reported a lack of confidence in the long-term management of all ENT conditions. When participants were asked about the specific conditions they were not confident in managing, $25 \%$ responded otitis media with effusion, whilst the remaining conditions ranged from $13-19 \%$.

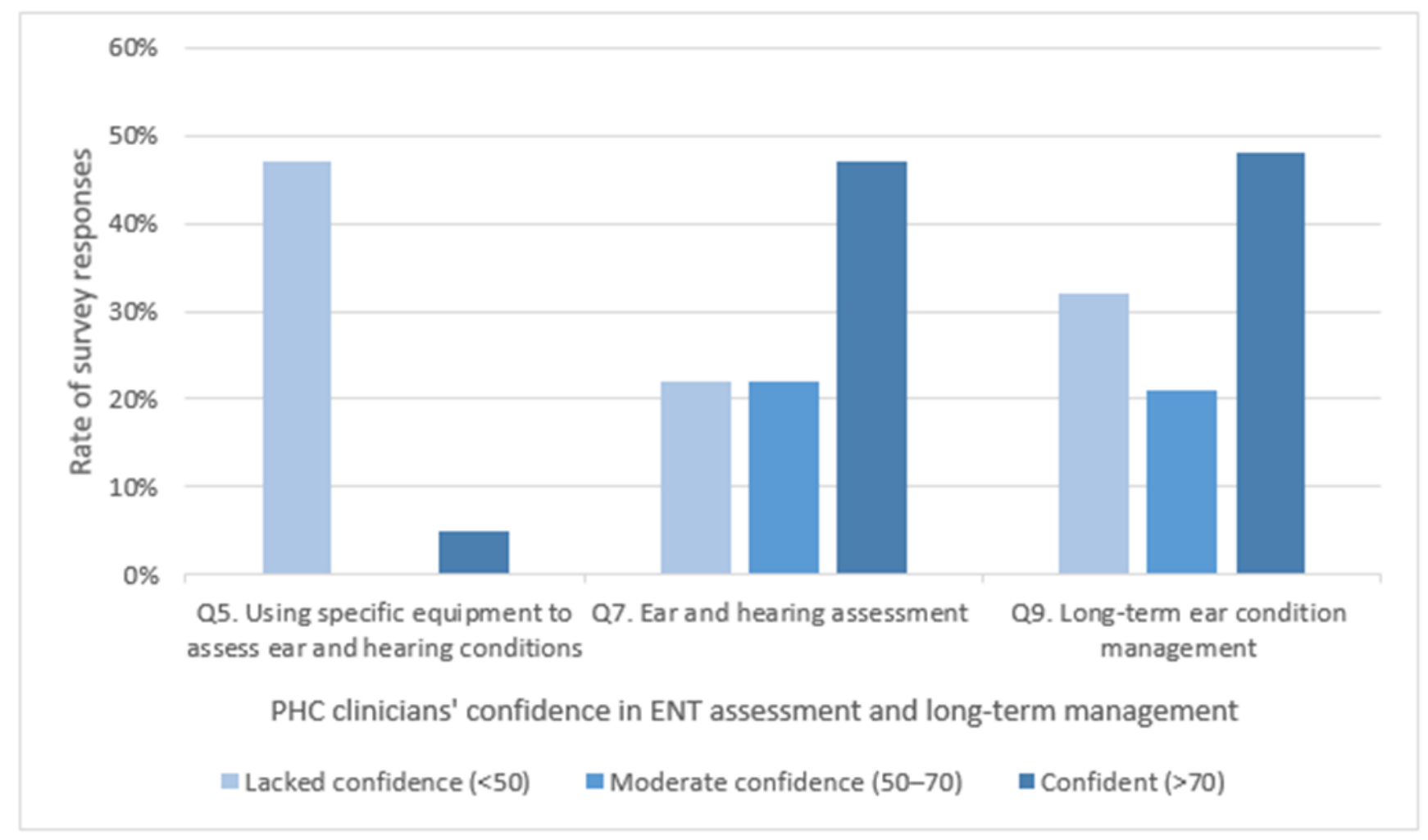

Figure 2. Clinician confidence at assessment, using ear-specific equipment and management of ear and hearing conditions.

\subsubsection{Telehealth}

Most of the respondents (81\%) reported that they considered telehealth consultations for ENT services would be well-received in the community. Additional comments for this section (see Table 1) suggested that telehealth would enable greater family involvement in health care, assisting patients in making informed decisions.

\subsubsection{Training and Further Education in Ear and Hearing Health}

The majority (84\%) of respondents said they would like to attend face-to-face ear and hearing education sessions. Furthermore, individual answers reiterated the importance of training and refresher courses to all staff, especially immediately after training to lock in newly learnt skills. The greatest level of interest $(100 \%)$ was for ear suctioning and tympanometry training). Interest was also high for long-term management of otitis media conditions $(80 \%)$, identification of different otitis media conditions $(60 \%)$, and how and when to refer to ENT specialists (73\%). Other comments made in the free text section highlighted the current issues with the available ENT services and the need to improve intra-agency communication to improve ENT services. 
Table 1. Unprompted, additional comments made in the primary health care (PHC) clinician survey.

\begin{tabular}{ll}
\hline \multicolumn{1}{c}{ Survey Question } & \multicolumn{1}{c}{ Additional Comments } \\
\hline Q12 Telehealth & "Rather than travelling for a consult this prepares families to \\
make better decision E choices for themselves about ENT services" & "Need for continual training and support for staff - also new \\
staff training" & "Those attending [a training session] should have ear health \\
Q14 and Q15 Training and & included in their clinical practice post-training and have strategic \\
Further Education & plans for using the training" \\
& "[There is a] lack of ENT service ... delays in ENT services ... \\
& lack of coordination of ENT services ... [and] lack of evidence of \\
& ENT interventions" \\
"Need to improve communication from leaders to clinicians, also, \\
intra-agency communication between service providers regarding \\
ENT services in the Cape. Improvements in communication will \\
assist clinicians on the ground know what is happening and to \\
avoid duplication of services"
\end{tabular}

\subsection{Stakeholder Forum and Follow-up Survey}

Twenty key stakeholders were invited to attend the open forum, of which 10 participants $(50 \%)$ attended. The follow-up survey was sent to the same 20 key stakeholders, which resulted in 18 participants $(90 \%)$ completing the survey. Stakeholders included child health and public health nurses, medical officers, and system administrators. Gaps and barriers in current ENT services were identified at the forum and then presented again at the follow-up survey for agreeance (Table 2). Stakeholders identified that, due to the lack of confidence in assessing and managing ear and hearing conditions, PHC clinicians often made inappropriate referrals to specialist services (Tables 2 and 3). As a result, these services experience long waiting times and, also, high rates of non-attendance. Another issue with referrals was that ENT specialists found that patient records would be regularly incomplete. Missing data meant specialists had to double up on services to get the essential information required for that day's appointment, resulting in the extra time needed with patients and increasing waiting times for future patients. Telehealth is not currently offered in the area. An overburdened system and high staff turnover could be reasons for the lack of take-up of telehealth services. Potential solutions, and their feasibility were then discussed, which were used as the building blocks for the new model of care. Four themes emerged from the forum and follow-up survey: (1) training for health workers in ENT management, (2) improved local service access, (3) new referral pathways to improve continuity of care, and (4) introduction of telehealth (Table 3).

Table 2. Gaps and barriers to current ear and hearing service delivery identified by forum stakeholders, and the rate of agreeance by follow-up survey respondents $(n=18)$.

\section{Identified Gaps/Barriers in Ear and Hearing Service Delivery}

Administration systems poorly functioning, i.e., referrals, appointment processes

Ear pathology difficult in PHC setting, making diagnosis by PHC clinicians poor

Ear condition management not always adhered to by PHC clinicians Telehealth not well supported by PHC clinicians

Specialist recommendations not adhered to by PHC clinicians
Rate of Agreeance by Follow-up Survey Respondents (\%)
$88 \%$

$71 \%$

$71 \%$

$53 \%$

$41 \%$

$41 \%$ 
Table 3. Themes, barriers, and solutions identified at stakeholder forum and follow-up survey.

\begin{tabular}{|c|c|}
\hline Identified Gaps/Barriers in Ear and Hearing Service Delivery & Potential Solutions \\
\hline \multicolumn{2}{|c|}{ Theme 1: Training for health workers in ENT management } \\
\hline $\begin{array}{l}\text { "Poor diagnostics skills in community for ear conditions- therefore } \\
\text { inappropriate management" }\end{array}$ & $\begin{array}{l}\text { "More health workers and nurses properly trained at } \\
\text { ground level" } \\
\text { "Appropriate management and hearing health promotion } \\
\text { funded more extensively and given more recognition } \\
\text { of need" }\end{array}$ \\
\hline
\end{tabular}

Theme 2: Improve local service access

"As a PHC GP I found that the service provision has been so infrequent that we basically have no ENT service in Cape York. Therefore all my clients are referred to Cairns which is sometimes very difficult for my patients to attend and they miss appointments"
"Regular visits by outreach specialists with the possibility to discuss in person regular review or follow up of the patients seen clear advice how to continue management or treatment"

"More regular visits to build rapport with communities so that recs are more likely to be followed"

Theme 3: New referral pathways to improve continuity of care

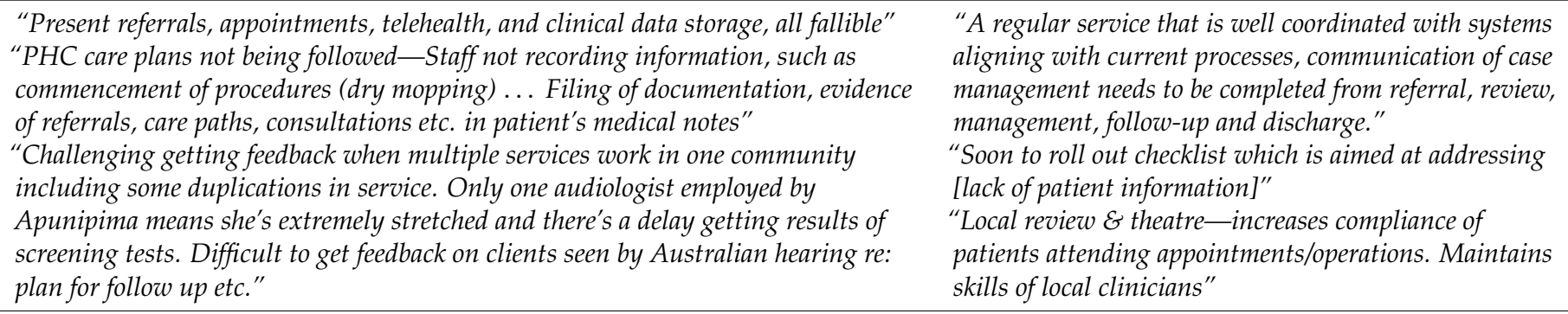

Theme 4: Introduction to telehealth

\begin{abstract}
"More telehealth with images sent from appropriate machines giving good images. Possibly an email link to consultants for guidance regarding management and a regular outreach audiometry service"

"Telehealth training: take otoscopic images and send them for review ... ENT/specialist who reviews them can be anywhere ... Train staffed to use digital otoscope and take pictures - less reliance on diagnostic skills"
\end{abstract}

"[ENT] services should be supported via telehealth but with lack of appropriate clinical support, turnover of staff, need for specialist equipment etc. implementation is proving difficult at this time."

\subsubsection{Theme 1: Training for Health Workers in ENT Management}

Stakeholders identified that the first step in improving current ENT services must include training all current and future PHC clinician staff (Table 3). Training would improve confidence in assessing and managing ear and hearing conditions, and the use of equipment needed. Additional hearing health promotion and funding is needed for this to be executed in this region.

\subsubsection{Theme 2: Improve Local Service Access}

Limited access to ENT services is a known barrier to healthcare for the region. As a result, improving local access needs to be a priority. Stakeholders would like to see access to ENT services in all thirteen communities. Furthermore, the high turnover of staff has been identified as an issue, due to a lack of consistency. Consistency of staff has the ability to improve health outcomes for patients, as they are likely to follow healthcare directives and come back for follow-up appointments.

\subsubsection{Theme 3: New Referral Pathways to Improve Continuity of Care}

Stakeholders identified that the recommended pathways for escalation to ENT specialist referral were inconsistent, which resulted in congested services. Patients have to travel 
far distances for specialist services, and, as a result, many do not show for appointments. Further, it was recognized that a lack of centralized coordination of ear health activities exacerbated the confusion around ENT care delivery, which results in frequent duplication in service. The new model of care will include a checklist for PHC clinicians, and it was recommended that regular monitoring is essential to ensure that new clinical pathways are adhered to by staff at all levels.

\subsubsection{Theme 4: Introduction to Telehealth}

Stakeholders have identified that PHC clinicians already have the capacity to use telehealth within their practice, but uptake is poor, potentially due to a lack of resources such as time, training, and equipment. Stakeholders strongly supported the use of telehealth, as it has the ability for PHC clinicians to get second opinions or advice by sending images to specialist services or other clinicians.

\section{Discussion}

Participatory action research allowed for input from 19 PHC clinicians, 10 face-to-face stakeholders' perspectives, and 18 stakeholder follow-up survey respondents in regard to the development of a new ENT model of care for Cape York. The aims were to outline PHC clinicians' current ENT concerns, to gain ENT stakeholders' perspectives in the current gaps and barriers to ENT services in the region, and to make recommendations for a new ENT service model. Findings from both surveys and the open discussion indicated stakeholders' highest priorities were clinical education and system improvement. They outlined that the current provision of specialist ENT services upon a poorly-functioning PHC service had created dependence on the ENT specialist for routine PHC level ear and hearing concerns. Their priorities were for training and greater investment in PHC level care, with improved referral systems and greater use of telehealth for timely ear review.

The four themes that emerged from this research echoed the missing features in the current service model. These themes included the need for ongoing training, improved access to services, improved referral pathways, and greater access to telehealth, once established, that could then be applied to the revision of the service model. Previous research demonstrated that the use of telehealth has the potential to reduce waiting times by $31 \%$ in remote Alaska $[7,26]$. A community-based mobile telehealth screening service in remote Australia for Aboriginal and Torres Strait Islander children was found to successfully provide specialist review and treatment planning at a distance [27]. Furthermore, a Queensland telehealth scoping review identified that face-to-face consultations for ENT consultations could be reduced by $89 \%$ if telehealth were used $[7,28]$.

The use of PAR in this study enabled service redesign that has developed a more relevant and appropriate service model than would otherwise have been developed [14,15]. As with other research in this area, PAR assists with maintaining the relationships behind the research objectives [14]. It takes the research a further step than undertaking only a literature review [15]; the practice of which has been criticized as ineffective as a sole approach to obtaining community or stakeholder involvement [15]. In combination with findings from the ENT referral review [11] and the economic costing, as previously described [29], PAR provided sufficient input for the development of a new ENT service model. It is also important to acknowledge that PAR can be selective or partial. Specifically, the use of PAR does limit the extent to which the findings from this research can be generalizable beyond this setting [30]. However, given the unique setting and population this study concerns, PAR has enabled a deeper understanding of current issues, and provided sustainable improvements for future services.

\section{Conclusions}

Participatory action research provided the avenue for stakeholder input that was sound, and their involvement in the process is more likely to create a sustainable model. Redesigned models that are tailored to local needs and to promote cross-agency collabora- 
tion are more likely to be successful and increase access to health services. This process of applying PAR methods to developing a new service delivery model may be utilized by other health services considering service redesign or revision, nationally or internationally. It is hoped that this method may act as a template for the redesign of other specialty health areas across this region.

Supplementary Materials: The following are available online at https:/ /www.mdpi.com/1660-460 1/18/1/167/s1, File S1: PHC clinician survey.

Author Contributions: All authors contributed significantly, critically revising and reviewing prior to submission. S.P.J. collected and analyzed the data and provided the first draft. L.E. re-analyzed the data and subsequently redesigned the manuscript for publication. I.K. reviewed all changes by L.E. and provided feedback throughout. All authors have read and agreed to the published version of the manuscript.

Funding: Queensland Health commissioned the service redesign. We received no funding for the writing up of this publication. IK is supported by the Health Research Board [ARPP-2020-011] Postdoctoral Fellowship 2020 'Applying Research into Policy \& Practice (ARPP)'.

Institutional Review Board Statement: The study was conducted according to the guidelines of the Declaration of Helsinki, and approved by the Far North Queensland Human Research Ethics Committee and granted an exemption from full ethical review, as it meets criteria as a quality improvement activity; reference number HREC/17/QCH/3-1111 QA.

Informed Consent Statement: Informed consent was waivered by the ethics committee as this constituted a CQI activity.

Data Availability Statement: All available data is provided here, no further data is available.

Acknowledgments: Denise Newman, Advanced Indigenous Health Worker, who assisted to coordinate the ENT Forum, and Kate McConnon who supported the redesign process throughout.

Conflicts of Interest: The authors declare no conflict of interest.

\section{Appendix A}

Table A1. Primary health care (PHC) clinician multiple choice survey responses.

\begin{tabular}{|c|c|}
\hline Survey Multiple Choice Options (Number of Responses) & $\mathbf{N}(\%)$ \\
\hline \multirow{2}{*}{\multicolumn{2}{|c|}{$\begin{array}{l}\text { Demographics of Respondents } \\
\text { Q1 Current working role in Cape York }(n=19)\end{array}$}} \\
\hline & \\
\hline Clinical Nurse & $8(42 \%)$ \\
\hline Medical Officer & $3(16 \%)$ \\
\hline Indigenous Health Worker & $2(11 \%)$ \\
\hline Nursing Manager & $2(11 \%)$ \\
\hline Audiologist & $1(5 \%)$ \\
\hline Visiting Specialist & $1(5 \%)$ \\
\hline Other (please specify) & $2(11 \%)$ \\
\hline \multicolumn{2}{|l|}{ Q2 Length in current role $(n=19)$} \\
\hline$\leq 3$ months & $1(5 \%)$ \\
\hline $3-6$ months & $0(0 \%)$ \\
\hline 7-12 months & $1(5 \%)$ \\
\hline 13 months -5 years & $13(68 \%)$ \\
\hline$\geq 6$ years & $4(21 \%)$ \\
\hline \multirow{2}{*}{\multicolumn{2}{|c|}{$\begin{array}{l}\text { Community Ear and Hearing Health Process Review } \\
\text { Q3 Work for any of the following primary health care providers? }(n=17)\end{array}$}} \\
\hline & \\
\hline Torres and Cape Hospital Health Service & $9(53 \%)$ \\
\hline Apunipima Cape York Health Council & $7(41 \%)$ \\
\hline Royal Flying Doctor Service & $3(18 \%)$ \\
\hline Deadly Ears Program & $1(6 \%)$ \\
\hline
\end{tabular}


Table A1. Cont.

\begin{tabular}{|c|c|}
\hline Survey Multiple Choice Options (Number of Responses) & $\mathbf{N}(\%)$ \\
\hline \multicolumn{2}{|l|}{ Q4 Equipment used to asses ear and hearing health $(n=18)$} \\
\hline Otoscope & $18(100 \%)$ \\
\hline Tympanometer & $13(72 \%)$ \\
\hline Audiometer & $6(33 \%)$ \\
\hline Video otoscope & $3(17 \%)$ \\
\hline Flexicam otoscope & $0(0 \%)$ \\
\hline \multicolumn{2}{|l|}{ Q5. Lack of confidence using specific equipment $(n=19)$} \\
\hline Audiometer & $9(47 \%)$ \\
\hline Tympanometer & $9(47 \%)$ \\
\hline Otoscope & $8(42 \%)$ \\
\hline Video otoscope & $8(42 \%)$ \\
\hline Flexicam otoscope & $8(42 \%)$ \\
\hline None- - I am confident using all equipment & $1(5 \%)$ \\
\hline \multicolumn{2}{|l|}{ Q6 Clinical care guidelines used when reviewing ear or hearing presentations $(n=19)$} \\
\hline Primary clinical care manual & $17(90 \%)$ \\
\hline Clinical care guidelines for treatment of otitis media in Aboriginal \& Torres Strait Islander populations & $8(42 \%)$ \\
\hline Clinical judgement & $7(37 \%)$ \\
\hline Therapeutic guidelines & $4(21 \%)$ \\
\hline Deadly Ears guidelines and protocols & $2(11 \%)$ \\
\hline Central Australian Rural Practitioners Association & $1(5 \%)$ \\
\hline Clinical Prioritisation Criteria & $0(0 \%)$ \\
\hline \multicolumn{2}{|l|}{ Q7 Confidence in making ear/hearing assessments $(n=18)$} \\
\hline Not confident $(<20)$ & $2(11 \%)$ \\
\hline Not very confident $(20-50)$ & $2(11 \%)$ \\
\hline A little confident (51-70) & $4(22 \%)$ \\
\hline Quite confident (71-90) & $7(40 \%)$ \\
\hline Very confident $(>90)$ & $3(7 \%)$ \\
\hline \multicolumn{2}{|l|}{ Q8 Conditions you're unsure of in your ear assessments $(n=18)$} \\
\hline Otitis media effusion & $8(44 \%)$ \\
\hline Acute otitis media & $4(22 \%)$ \\
\hline Acute otitis media without perforation & $4(22 \%)$ \\
\hline Acute otitis media with perforation & $4(22 \%)$ \\
\hline Chronic suppurative otitis media & $4(22 \%)$ \\
\hline Dry perforation & $4(22 \%)$ \\
\hline None-confident in all assessments & $6(33 \%)$ \\
\hline Other (exostosis/osteoma $n=1$; early cholesteatoma $n=1$ ) & $2(11 \%)$ \\
\hline \multicolumn{2}{|l|}{ Q9 Confidence in long-term ear condition management $(n=19)$} \\
\hline Not confident $(<20)$ & $3(16 \%)$ \\
\hline Not very confident $(20-50)$ & $3(16 \%)$ \\
\hline A little confident (51-70) & $4(21 \%)$ \\
\hline Quite confident (71-90) & $6(32 \%)$ \\
\hline Very confident $(>90)$ & $3(16 \%)$ \\
\hline \multicolumn{2}{|l|}{ Q10 Lack of confidence in managing conditions $(n=16)$} \\
\hline Otitis media with effusion & $4(25 \%)$ \\
\hline Acute otitis media with perforation & $3(19 \%)$ \\
\hline Chronic suppurative otitis media & $3(19 \%)$ \\
\hline Dry perforation & $3(19 \%)$ \\
\hline Acute otitis media & $2(13 \%)$ \\
\hline Acute otitis media without perforation & $2(13 \%)$ \\
\hline None-I'm confident in all of them & $8(50 \%)$ \\
\hline \multicolumn{2}{|l|}{ Q11 Reasons for referral to medical or ENT specialist for advice $(n=19)$} \\
\hline To refer for surgery & $15(79 \%)$ \\
\hline For a second opinion on a clinical decision & $14(74 \%)$ \\
\hline To take over patient ear condition management & $12(63 \%)$ \\
\hline For ear condition management advice & $12(63 \%)$ \\
\hline Other (if not seen in timely manner) & $1(5 \%)$ \\
\hline
\end{tabular}


Table A1. Cont.

\begin{tabular}{|c|c|}
\hline Survey Multiple Choice Options (Number of Responses) & $\mathbf{N}(\%)$ \\
\hline \multicolumn{2}{|l|}{ Q12 Telehealth for ENT consults $(n=16)$} \\
\hline I consider they would be well received & $13(81 \%)$ \\
\hline No-I don't think they would be well received & $3(19 \%)$ \\
\hline Q13 Would community members (patient/carers) welcome Ear Health information to take home? $(n=17)$ & \\
\hline I consider this would be well received & $10(83 \%)$ \\
\hline No-I don't consider they would be well received & $2(17 \%)$ \\
\hline \multicolumn{2}{|l|}{ Q14 Face-to-face ear and hearing training for PHC clinicians $(n=19)$} \\
\hline Yes & $16(84 \%)$ \\
\hline No & $0(0 \%)$ \\
\hline Other & $3(16 \%)$ \\
\hline \multicolumn{2}{|l|}{ Q15 Specifically, what training interests you $(n=15)$} \\
\hline Ear suctioning and tympanometry & $15(100 \%)$ \\
\hline Long-term community management of otitis media & $12(80 \%)$ \\
\hline How and when to seek specialist ENT input (referral) & $11(73 \%)$ \\
\hline Use of current guidelines for treatment and management of ear disease & $11(73 \%)$ \\
\hline Identification of different otitis media conditions & $9(60 \%)$ \\
\hline All of the above & $2(13 \%)$ \\
\hline
\end{tabular}

\section{References}

1. Australian Bureau of Statistics. Australian Aboriginal and Torres Strait Islander Health Survey: First Results, Australia, 2012-2013; Australian Bureau of Statistics: Canberra, Australia, 2013

2. Gruen, R.L.; Bailie, R.S.; Wang, Z.; Heard, S.; O'Rourke, I.C. Specialist outreach to isolated and disadvantaged communities: A population-based study. Lancet 2006, 368, 130-138. [CrossRef]

3. Wakerman, J.; Humphreys, J.S.; Wells, R.; Kuipers, P.; Entwistle, P.; Jones, J. Primary health care delivery models in rural and remote Australia: A systematic review. BMC Health Serv. Res. 2008, 8, 276. [CrossRef] [PubMed]

4. Australian Bureau of Statistics. Population by Age and Sex, Regions of Australia. In Regional Population Growth, Australia, 2013-2014; Australian Bureau of Statistics: Canberra, Australia, 2014.

5. Gunasekera, H.; Morris, P.S.; Daniels, J.; Couzos, S.; Craig, J.C. Otitis media in Aboriginal children: The discordance between burden of illness and access to services in rural/remote and urban Australia. J. Paediatr. Child Health 2009, 45, 425-430. [CrossRef] [PubMed]

6. Begg, S.; Bright, M.; Harper, C. Burden of Disease and Injury, Life Expectancy and Health-Adjusted Life Expectancy in Queensland Health Service Districts, 2006; Queensland Health: Brisbane, Australia, 2009.

7. Jacups, S.P.; Newman, D.; Dean, D.; Richards, A.; McConnon, K.M. An innovative approach to improve ear, nose and throat surgical access for remote living Cape York Indigenous children. Int. J. Pediatr. Otorhinolaryngol. 2017, 100, 225-231. [CrossRef] [PubMed]

8. Children's Health Queensland Hospital and Health Service. Deadly Ears; 2020. Available online: https://www.childrens.health. qld.gov.au/chq/our-services/community-health-services / deadly-ears/ (accessed on 12 November 2020).

9. Children's Health Queensland Hospital and Health Service. Deadly Ears Program; 2020. Available online: https://www. childrens.health.qld.gov.au/service-deadly-ears-program/ (accessed on 12 November 2020).

10. Free Map Tools. Measure a Distance. n.d. Available online: https://www.freemaptools.com/measure-distance.htm (accessed on 12 November 2020).

11. Jacups, P.S.; McConnon, K.M. Reducing ear, nose and throat (ENT) waitlists: Implications of a referral audit. Health Policy 2019, 123, 333-337. [CrossRef] [PubMed]

12. Queensland Government. Waiting Lists. Hospital Care, Surgical Procedures and Waiting Lists. 2015. Available online: https:/ / www.qld.gov.au/health/services/hospital-care/waiting-lists (accessed on 12 November 2020).

13. Baum, F.; MacDougall, C.; Smith, D. Participatory action research. J. Epidemiol. Community Health 2006, 60, 854-857. [CrossRef]

14. Andersson, N. Participatory research-A modernizing science for primary health care. J. General Fam. Med. 2018, 19, 154-159. [CrossRef]

15. Harris, J.; Cook, T.; Gibbs, L.; Oetzel, J.; Salsberg, J.; Shinn, C.; Springett, J.; Wallerstein, N.; Wright, M. Searching for the Impact of Participation in Health and Health Research: Challenges and Methods. Biomed. Res. Int. 2018, 2018. [CrossRef]

16. Boote, J.; Wong, R.; Booth, A. Talking the talk or walking the walk? A bibliometric review of the literature on public involvement in health research published between 1995 and 2009. Health Expect 2015, 18, 44-57. [CrossRef]

17. Feldmann, J.; Puhan, M.A.; Mütsch, M. Characteristics of stakeholder involvement in systematic and rapid reviews: A methodological review in the area of health services research. BMJ Open 2019, 9, e024587. [CrossRef]

18. Kokesh, J.; Ferguson, A.S.; Patricoski, C. Telehealth in Alaska: Delivery of health care services from a specialist's perspective. Int. J. Circumpolar Health 2004, 63, 387-400. [CrossRef] 
19. Kokesh, J.; Ferguson, A.S.; Patricoski, C. Preoperative planning for ear surgery using store-and-forward telemedicine. Otolaryngol. Head Neck Surg. 2010, 143, 253-257. [CrossRef]

20. Smith, A.C.; Armfield, N.R.; Wu, W.I.; Brown, C.A.; Perry, C. A mobile telemedicine-enabled ear screening service for Indigenous children in Queensland: Activity and outcomes in the first three years. J. Telemed. Telecare 2012, 18, 485-489. [CrossRef] [PubMed]

21. Wakerman, J. Innovative rural and remote primary health care models: What do we know and what are the research priorities? Aust. J. Rural Health 2009, 17, 21-26. [CrossRef] [PubMed]

22. Watson, D.S.; Clapin, M. Ear health of aboriginal primary school children in the Eastern Goldfields Region. of Western Australia. Aust. J. Public Health 1992, 16, 26-30. [CrossRef] [PubMed]

23. Reeve, C.; Thomas, A.; Mossenson, A.; Reeve, D.; Davis, S. Evaluation of an ear health pathway in remote communities: Improvements in ear health access. Aust. J. Rural Health 2014, 22, 127-132. [CrossRef] [PubMed]

24. Watson, J.; Gasser, L.; Blignault, I.; Collins, R. Taking telehealth to the bush: Lessons from north Queensland. J. Telemed. Telecare 2001, 7, 20-23. [CrossRef] [PubMed]

25. National Health and Medical Research Council. Ethical Considerations in Quality Assurance and Evaluation Activities; Australian Government: Canberra, Australia, 2014.

26. Hofstetter, P.J.; Kokesh, J.; Ferguson, A.S.; Hood, L.J. The Impact of Telehealth on Wait Time for ENT Specialty Care. Telemed. EHealth 2010, 16, 551-556. [CrossRef] [PubMed]

27. Elliott, G.; Smith, A.C.; Bensink, M.E.; Brown, C.; Stewart, C.; Perry, C.; Scuffham, P. The feasibility of a community-based mobile telehealth screening service for Aboriginal and Torres Strait Islander children in Australia. Telemed. J. E-Health 2010, 16, 950-956. [CrossRef]

28. Caffery, L.J.; Farjian, M.; Smith, A.C. Telehealth interventions for reducing waiting lists and waiting times for specialist outpatient services: A scoping review. J. Telemed. Telecare 2016, 22, 504-512. [CrossRef]

29. Jacups, S.P.; Kinchin, I.; McConnon, K.M. Ear, nose, and throat surgical access for remote living Indigenous children: What is the least costly model? J. Eval. Clin. Pract. 2018, 24, 1330-1338. [CrossRef] [PubMed]

30. Mackenzie, J.; Tan, P.L.; Hoverman, S.; Baldwin, C. The value and limitations of Participatory Action Research methodology. J. Hydrol. 2012, 474, 11-21. [CrossRef] 